\title{
INGLESES DENTRO E FORA DA ESCOLA PÚBLICA: PRÁTICAS LOCAIS EM LÍNGUA ADICIONAL
}

\author{
INGLÉSES DENTRO Y FUERA DE LA ESCUELA PÚBLICA: PRÁCTICAS LOCALES EN LENGUA ADICIONAL \\ ENGLISHES IN AND OUT OF PUBLIC SCHOOL: LOCAL PRACTICES IN ADDITIONAL LANGUAGE \\ Igor Gadioli* \\ Universidade Federal de Sergipe - UFS, São Cristóvão, BR
}

\begin{abstract}
RESUMO: Práticas de ensino/aprendizagem de Inglês no Ensino Médio da escola pública são frequentemente orientadas para demandas do vestibular, do mercado de trabalho e dos modelos linguísticos de "falantes nativos". Tais perspectivas tornam-se meramente utilitárias ao ignorarem necessidades e expectativas locais dos estudantes. Nesse contexto, usos alternativos do idioma dentro e fora da escola, por meio de casas seguras (CANAGARAJAH, 2004), dão vazão a propósitos ideológicos dos alunos. Esses usos produzem variantes linguísticas inovadoras, que no caso do inglês podem ser chamadas de ingleses (MOITA LOPES, 2008). As atuações linguísticas inventivas e as implicações que elas têm para a trajetória social dos usuários sugerem uma reconsideração das diretrizes escolares para o ensino de línguas adicionais.

PALAVRAS-CHAVE: ingleses; escola pública; casas seguras.
\end{abstract}

RESUMEN: Las prácticas de enseñanza/aprendizaje de inglés en escuelas públicas de enseñanza media son frecuentemente orientadas a las exigencias del vestibular, del mercado laboral y de los modelos lingüísticos de los nativos. Tales perspectivas se convierten en meramente utilitarias al ignorar las necesidades y las expectativas locales de los estudiantes. En este contexto, los usos alternativos de la lengua dentro y fuera de la escuela a través de casas seguras (CANAGARAJAH, 2004) dan rienda suelta a los propósitos ideológicos de los estudiantes. Estos usos producen variantes lingüísticas innovadoras, que en el caso del inglés pueden ser llamadas de "ingleses" (MOITA LOPES, 2008). Las actuaciones lingüísticas inventivas y las implicaciones que estas tienen para la trayectoria social de los usuarios sugieren una reconsideración de las directrices para la enseñanza de las lenguas adicionales.

PALABRAS-CLAVE: ingleses; la escuela pública; casas seguras.

ABSTRACT: Teaching/learning practices of English at high school in public schools are often oriented to demands of the marketplace, university entrance examinations, and linguistic models of "native speakers". Such orientation becomes merely utilitarian whenever they ignore local needs and expectations of students. In this context, alternative uses of language in and out of school, through pedagogical safe houses (CANAGARAJAH, 2004), allow students' ideological purposes to ensue in language practice. Such uses produce innovative language variants, which are called englishes (MOITA LOPES, 2008). Inventive language performances and the implications they have for the social trajectory of language users suggest we may rethink school orientations towards the teaching of additional languages.

KEYWORDS: Englishs; public school; pedagogical safe houses.

\section{INTRODUÇÃO}

Este artigo foi produzido a partir de minha pesquisa de mestrado ${ }^{1}$, de caráter etnográfico, realizada com alunos de Ensino Médio em uma escola pública de Florianópolis entre 2010 e 2012, cujo objetivo era identificar como alunos resistiam e se acomodavam a práticas de linguagem dentro e fora da aula de Inglês como língua adicional. Nela, fiz investigações durante aulas de Inglês e também durante momentos fora de sala de aula a partir de uma perspectiva etnográfica. Para tanto, utilizei recursos típicos dessa tradição de pesquisa, tais como observação participante e entrevistas semi-estruturadas gravadas em áudio. Uma de minhas constatações foi a de como práticas de ensino/aprendizagem de Inglês no Ensino Médio podem ser institucionalmente orientadas por demandas do vestibular, do mercado de trabalho e dos modelos linguísticos de "falantes nativos".

\footnotetext{
* Mestre em linguística pela Universidade Federal de Santa Catarina e professor efetivo de língua inglesa e portuguesa da Universidade Federal de Sergipe, Campus I (São Cristóvão), lotado no Núcleo de Secretariado Executivo. E-mail: igorgadioli@gmail.com. 
Práticas pedagógicas baseadas em orientações dominantes como as citadas acima se tornam meramente utilitárias à medida que ignoram necessidades e expectativas locais dos estudantes. Nesse contexto, usos alternativos do idioma contemplam manifestações identitárias localmente construídas, dando vazão a propósitos ideológicos dos alunos. Tais propósitos nem sempre coincidem com aqueles estabelecidos por instâncias de poder (docentes, currículo escolar, etc.), ainda que ajudem os alunos a desenvolver competências em língua inglesa para usos diversos como brincadeiras com colegas, jogos on-line ou mesmo interações com estrangeiros. Os propósitos ideológicos dos alunos transparecem na própria estrutura do inglês que aprendem, o qual a um só tempo viabiliza e emerge de tais usos.

Na seção a seguir, abordo o caráter dos usos e das estruturas da língua inglesa enquanto instrumento ideológico e discuto como tais produções nessa língua possibilitam a construção local de práticas sociais. Ao fazê-lo, contemplo ainda as relações de poder imbricadas nos parâmetros de sucesso linguístico estipulados pela escola e baseados no mito do falante nativo.

\section{LINGUAGEM COMO PRÁTICA LOCAL}

O conceito de linguagem como prática local (PENNYCOOK, 2010) se vale da premissa de que línguas são contingentes aos usos que seus falantes fazem delas localmente, quando da realização de múltiplas atividades sociais. Austin (1962) já vislumbrava a natureza social da linguagem ao perguntar como fazemos coisas com as palavras; Pennycook, entretanto, reformulou esse questionamento para demonstrar que a prática social em si já implica em produção de linguagem: "como é que as coisas que nós fazemos produzem linguagem?” (2010, p. 17), pergunta o autor. Nesse ínterim, Pennycook define linguagem como

[...] um produto de atividades sociais e culturais nas quais as pessoas se engajam profundamente. [...] Olhar a linguagem como prática é ver a linguagem como uma atividade e não como uma estrutura, como algo do qual nos valemos, como uma parte material da vida social e cultural ao invés de uma entidade abstrata $^{2}$ (PENNYCOOK, 2010, p.1-2).

Essa definição de linguaguem a vislumbra como co-construída em interações sociais, simultaneamente constituída e constituinte do fazer social (GADIOLI, 2012). Ela permite compreender a proficiência em línguas como contingente ao sucesso de interações locais (PENNYCOOK, 2010, CANAGARAJAH, 2006); tal visão ressignifica, por conseguinte, o papel de modelos pré-estabelecidos por variantes de prestígio derivado de locais de nascimento, poder econômico e cor de pele (SHARIFIAN, 2009). Aqui, o desempenho linguístico depende da negociação de significado em diferentes comunidades de prática, as quais podem incluir falantes "nativos" ou não. O uso de variantes linguísticas dominantes perde importância em favor das redes de significação locais emergentes, nas quais o êxito interacional depende de aspectos culturais, sociais e políticos não contemplados pelo binarismo "falante nativo vs. falante não-nativo". Nessa perspectiva, Canagarajah esclarece que "a gramática [bem como outros componentes linguísticos] é sempre emergente, e não pré-definida $[\ldots .$.$] a forma não governa os falantes de uma língua, falantes negociam a forma para usá-$ la para seus interesses" $(2008, \mathrm{p} . \mathrm{IX}-\mathrm{X}) .^{3}$

Esse conceito de linguagem como prática local é útil na investigação dos usos do inglês que rejeitam a visão dessa língua como commodity e/ou objeto de consumo (CORACINI, 2003; JORDÃO, 2004; PENNYCOOK, 2004). Ainda que o uso formal da língua inglesa na escola se atenha a variantes hegemônicas, os alunos podem desconstruir padrões de uso, resistindo a essa hegemonia de forma a usar o inglês para finalidades alternativas. Ao promover reapropriações desse caráter, esses estudantes agem por meio desse idioma valendo-se

\footnotetext{
[d]o seu uso transimperial, que possibilita a reinvenção da vida local não como mímica de designs globais, mas como possibilidade de construir uma outra globalização, anti-hegemônica, em performances linguístico-identitárias inovadoras nos fluxos da fronteira. [...] Os donos desses ingleses são, dessa forma, aqueles que os usam e fazem deles o que desejam, se re-inventando em novas performances identitárias e recriando o mundo. (MOITA LOPES, 2008, p. 309-334) (ênfase minha).
}

\footnotetext{
2 No original: "a product of the deeply social and cultural activities in which people engage. [...] To look at language as a practice is to view language as an activity rather than a structure, as something we do rather than a system we draw on, as a material part of social and cultural life rather than an abstract entity".

3 No original: "Grammar is always emergent, not predefined [...] form doesn't govern the speakers of language, speakers negotiate with form to use it for their interests".
} 
Esses ingleses, portanto, podem assumir um importante papel de transformação social ao facilitar a consideração de novas possibilidades de futuro. Eles enfatizam "a marca pós-colonial, fluida e contingente do local marginal(izado) em oposição a práticas dominantes [de linguagem].” (GADIOLI, 2012, p.36). Dentro da escola, esses ingleses também servem para fortalecer o elo de pequenos grupos. Clemente e Higgins (2008), por exemplo, relatam uma prática desse caráter por alunos mexicanos de Inglês como língua adicional. Eles usavam o falso cognato donkey em tom de brincadeira a fim de criticar o desempenho acadêmico de amigos; já Rampton (2006, p.175) trata de reapropriações locais de estudantes britânicos de Alemão como língua adicional, denominando-as impromptu Deutsch. O termo se deve ao fato de que essas produções eram concebidas pelos alunos de forma improvisada, no momento em que sentiam a necessidade para tal uso. Com o objetivo de evitar sanções de professores ou de outras figuras de autoridade, reapropriações linguísticas desse caráter podem ocorrer num contexto reservado. É à conceituação de contextos assim que me volto na seção a seguir. Ao fazê-lo, busco contemplar algumas formas de manifestação dos ingleses dentro e fora da sala de aula de Inglês como língua adicional.

\section{PRÁticAS DE LINGUAGEM EM CLIQUES E CASAS SEGURAS}

Os ingleses que os alunos constroem localmente podem não ser legitimados pela escola; essa é uma motivação para que produções linguísticas assim ocorram nas chamadas "casas seguras" (CANAGARAJAH, 2004). Esse conceito diz respeito a espaços reservados de figuras de autoridade (como professores, por exemplo) nos quais práticas de linguagem subversivas, tais como usos de ingleses, têm mais espaço para se manifestar sem coerções. Dado o caráter familiar e seguro dessa vida comunitária, utilizo a tradução de "casas seguras" para o termo, tal como o fiz em trabalho anterior (GADIOLI, 2012), ainda que ele tenha sido originalmente cunhado como pedagogical safe houses (CANAGARAJAH, 2004) e traduzido como "zonas pedagógicas de segurança” (CANAGARAJAH, 2009).

É ainda importante ressaltar que, ao tratar de casas seguras, Canagarajah apenas estendeu o então já existente conceito de safe houses (PRATT, 1991) ao contexto de ensino/aprendizagem. A acepção original do termo não trata das suas implicações para esse cenário em particular, referindo-se simplesmente a "espaços sociais e culturais onde grupos podem se constituir como comunidades horizontalizadas, homogêneas, com altos graus de confiança, entendimentos compartilhados e proteção temporária dos legados de opressão” (PRATT 1991, p.40). ${ }^{4}$

Um dos aspectos que garantem a privacidade de casas seguras é a forma como a linguagem se manifesta nelas: de forma sutil e discreta, frequentemente por meio do humor e da paródia (SCOTT, 1985 apud CANAGARAJAH 1999, p.92). Nesse contex to dentro da escola,

[os] alunos se proveem com sustentação e solidariedade social, emocional e psicológica contra a flagrante falta de vida e tendências reprodutivas [...] ao se comunicarem por cochichos secretos, trocarem recados e mensagens entre si, desviando das orientações institucionais escolares e enganando o professor, os alunos desfrutam de uma vida comunitária secreta e de uma dimensão curricular e cultural que significa muito para eles. (CANAGARAJAH, 1999, p.92-93, tradução minha). ${ }^{5}$

As interações em segredo, próprias da casa segura, podem ocorrer em pequenos grupos denominados por alguns autores, em língua inglesa, como cliques (BRUCKERHOFF, 1991; CLEMENTE; HIGGINS, 2008). Esse termo se refere a grupos identitariamente coesos e, em português, já foram chamados de "panelinhas" (FONTANA; ROTTAVA, 2009). A fim de evitar um termo já utilizado com uma carga semântica pejorativa em português, escolho aqui tomar emprestado o termo diretamente do inglês, "cliques", tal como fiz em trabalho anterior (GADIOLI, 2012).

As casas seguras construídas dentro de cliques podem facilitar e motivar o uso de ingleses dentro e também fora da escola. Essa relação entre usos subversivos de linguagem e privacidade se mostra importante para a construção da própria identidade desses grupos de forma mais segura e reservada. Na seção a seguir, volto-

\footnotetext{
4. No original: "social and intellectual spaces where groups can constitute themselves as horizontal, homogeneous, sovereign communities with high degrees of trust, shared understandings, and temporary protection from legacies of oppression”.

5 No original: “ $[\ldots]$ students collaborate in providing social, emotional and psychological sustenance and solidarity against the perceived lifelessness and reproductive tendencies of the course [...] By communicating through secretive whispers, exchanging notes and messages among themselves, deviating from the classroom agenda, and cheating the teacher, students enjoy a secret community life and a dimension of curriculum and culture that means a lot to them".
} 
me para um dos cliques que conheci em campo, delineando antes as características gerais da escola e da turma em que eles se inseriam.

\section{BREVE CONTEXTUALIZAÇÃO DO CENÁRIO DA PESQUISA}

A Escola do Desterro ${ }^{6}$ ficava num bairro de classe média baixa em Florianópolis/SC; era pacata e organizada, com pouco mais de 60 anos de funcionamento, cerca de dois mil alunos matriculados e boas condições estruturais para o andamento das aulas. As aulas de Inglês na turma do $1^{\circ}$ ano (turma da qual os participantes deste estudo faziam parte) se baseavam no estudo gramatical declarativo e de interpretação de texto via resgate de informação. A professora de Inglês dessa turma chamava-se Rose, que tinha então 48 anos e lecionava há 24. Ela era licenciada em Letras/Inglês pela UFSC e à época ensinava cerca de 510 alunos.

Dos estudantes que conheci, suas idades variavam entre 15 e 17 anos, e pelo menos um terço deles ingressou no mercado de trabalho ainda no ensino médio. A turma do $1^{\circ}$ ano de que trato aqui continha diversos cliques, frequentemente fechados em si em termos de interação. Para os alunos, isso possibilitava uma zona de conforto não só com relação à interação, mas também com relação à própria aprendizagem. Nesse interim, conheci o agitado clique de Juliano e Daniel, o qual destoava da dinâmica dos outros grupinhos da turma. Eles sentavam sempre juntos, um atrás do outro, próximos à professora e juntos à janela. Ambos tinham 17 anos quando os conheci. No período de 2011 no qual pude vê-los juntos em sala, muitos foram os dados e reflexões relevantes para a pesquisa. Seus usos da língua inglesa e o caráter de suas participações em sala de aula apontavam alternativas para o uso canônico do idioma, e é para tais alternativas que volto minha narrativa na seção a seguir.

\section{INGLESES DENTRO E FORA DA ESCOLA PÚBLICA: PRÁTICAS LOCAIS EM LÍNGUA ADICIONAL}

Durante as aulas de Inglês, Daniel frequentemente se valia do humor e forma a promover aprendizagem (CANAGARAJAH, 1997). Ele nunca havia estudado Inglês fora da escola regular, mas dominava o conteúdo das aulas e também participava ativamente das lições. Rose, a professora da turma, comentou que "ele tinha vontade de aprender [...] fez uma apresentação sobre nome, onde mora e onde nasceu e conseguiu apresentar direitinho” (ENTREVISTA, 01/03/2012). Seu interesse pelo idioma surgiu com jogos on-line: "jogo mais CS, Ragnarok, Grand Chase, Point Blank ${ }^{7}[\ldots]$ desde pequeno eu jogo, eu leio o que tá em inglês, aí eu vou jogando e lá na frente entendo o que aquela parte significava” (ENTREVISTA, 09/03/2012). Quando mais novo, solicitava ajuda de amigos para interagir nos bate-papos, comuns em jogos on-line, ajuda essa que mais tarde deixou de ser necessária.

Daniel jogava on-line em um servidor coreano, pois diferentemente de outros servidores, lá a maioria dos recursos era gratuita. De acordo com Daniel, “os coreanos falam um inglês diferente, mais difícil de compreender". Ele disse ainda achar que "o inglês de lá é diferente porque eles ensinam diferente, não sei” (ENTREVISTA, 09/03/2012). Sua observação demonstra, conforme discuti anteriormente (GADIOLI, 2012), uma sensibilidade dialetal e transcultural para uma variante do inglês que aparentemente não se encaixa bem nos parâmetros dominantes do idioma. Enquanto um olhar a partir de variantes hegemônicas poderia classificar essa prática on-line como desinteressante para um aprendiz de línguas, o conceito de linguagem como prática local (PENNYCOOK, 2010) permite o entendimento desse inglês coreano como legítimo por ser fruto de uma prática de linguagem que funciona no contexto daquele servidor on-line. É a relação social com aquela comunidade que agrega sentido não só à prática do jogo com mais recursos grátis, mas também ao inglês coreano que se constrói ao passo que tais práticas ocorrem.

\footnotetext{
6 Tanto o nome da escola como dos participantes de pesquisa são fictícios.

7 Ragnarok e Grand Chase são MMORPG (Massively multiplayer online role-playing game, jogos de RPG online); Point Blank e CS, por sua vez, são jogos táticos de tiro em primeira pessoa. As estruturas linguísticas noschats desses jogos tendem a ser restritas, pois jogadores geralmente se limitam a interações relacionadas à disputa on-line. De acordo com Juliano, jogador e amigo de Daniel, "agente fla [fala] kill the efc, come to help me, heal me, drop the flag, take the flag, u is noob [você é um novato] wtf [what the fuck], [basicamente comandos-chave].” (ENTREVISTA VIA FACEBOOK, 16/04/2012).
} 
A fala de Daniel e sua inserção exitosa naquela comunidade coreana legitimam o inglês usado como uma prática local (PENNYCOOK, 2010). Abordar essa sua experiência transcultural em sala de aula seria relevante; apesar disso, a professora Rose sequer tinha conhecimento desse seu uso da língua, pois ele ocorria em uma casa segura à parte da escola e alternativa à instrução formal do Inglês. Práticas semelhantes a essa adentravam a própria escola: Daniel também praticava inglês de formas alternativas e "secretas" durante as aulas.

Ele demonstrava um domínio linguístico que ia além do requisitado nas em sala de aula, e trata disso no trecho de entrevista a seguir: "Eu tou mais avançado, assim... Daí o pessoal fica meio pra trás, eu faço as coisas rápido, daí tem que ficar sem fazer nada...” (ENTREVISTA, 09/03/2012). Nesse contexto, sua agência era canalizada para brincadeiras, as quais frequentemente tinham relevância pedagógica (CANAGARAJAH, 1997). Daniel e Juliano (seu colega de clique) brincavam com o idioma e com colegas de sala de aula, subvertendo e reapropriando o inglês em favor de suas expectativas e necessidades. Uma dessas reapropriações aparece nesta vinheta:

Num exercício em sala, Rose tenta abordar a sonoridade de shrink com seus alunos, palavra que aparece
no texto de hoje. Remete a shrimp, mas poucos conseguem associar uma palavra à outra, visto que ambas
eram novas para a maioria deles. Vendo aquele impasse, Juliano se voluntaria a ajudar, dizendo, "é como
Shrek", e rapidamente aproveita para subverter a pronúncia: "é tipo "/sreki/"” - e repete o termo
diversas vezes, até que a maioria passa a entender "xereca". Todos riem, inclusive eu; já Rose faz uma
cara de certa reprovação, mas não chega a brigar com Juliano. (NOTAS DE CAMPO, $31 / 08 / 2011$ ).

A brincadeira de Juliano subverte o termo em inglês, associando-o a referências familiares para outros alunos. Já a professora parece perceber que essas brincadeiras ajudam a compor o contexto daquela aula, tanto em termos de relacionamento como em termos de aprendizagem. Ao promover esse tipo de contribuição, esses alunos exercitam um inglês alternativo (tal como o "coreano") que dá vazão a uma prática de maior relevância dentro de suas expectativas para com as aulas e com o próprio idioma.

Rampton (2006, p.62) menciona um caso semelhante de reapropriação linguística do Alemão como língua adicional envolvendo alunos de uma escola pública britânica. Nele, o idioma também é (re)construído improvisadamente com finalidades lúdicas e/ou de aprendizagem; Rampton denominou esse uso de impromptu Deustch por conta de seu caráter inventivo e espontâneo. Tanto em aulas de Inglês como de Alemão, seja no Brasil ou na Inglaterra, constatamos reapropriações linguísticas (ingleses e "alemães") que informam e embelezam as aulas, inibindo um potencial desinteresse dos que dominam certos conteúdos escolares e construindo um senso local de comunidade com instâncias de língua igualmente locais.

Para Juliano e Daniel, esse senso de comunidade derivado do inglês de suas brincadeiras também constituía uma casa segura, pois outros alunos frequentemente não compreendiam seus usos alternativos do idioma em sala de aula. Na entrevista abaixo, Daniel cita um exemplo desse inglês de entendimento restrito e fala da motivação para tais criações linguísticas:

Igor: Vocês ficavam brincando com uns negócios em inglês, vocês tinham umas brincadeirazinhas [nas aulas]...

Daniel: Com Gustavo.

Igor: Que brincadeira que era?

Daniel: Ah cara, a gente [ele e Juliano] tem a mania de chamar ele de adubo, não sei porque, aí começamos a chamar ele de manure [/'mənu,ri/ $]$, que foi a professora que disse que era adubo em inglês. Aí a gente ficava o tempo todo falando isso pra ele, daí. A gente ficava perguntando à professora como é que falava algumas coisas assim em inglês, que a gente não sabia, ela respondia... só isso.

Igor: Aí vocês começavam a usar, né.

Daniel: É. Só que daí ninguém entendia e nós ficava rindo.

Igor: ah, tô ligado. Agora, ele entendia, porque ele ouviu vocês perguntando à professora.

Daniel: Sim, ele ouviu. (ENTREVISTA, 09/03/2012).

Essa reapropriação linguística por meio de um inglês "de brincadeira" é também a reapropriação de uma prática social. A pronúncia do termo que a princípio seria "/,mə'njoər/" de acordo com a variante padrão do 
inglês estadunidense ${ }^{8}$, transforma-se aqui em /'mənu,ri/; nesse novo uso, o termo serve como brincadeira entre amigos, o que ajuda a compor a experiência escolar de cumplicidade desses jovens. A palavra em inglês, aqui, não depende da chancela de seu uso dominante, visto que a prática local que ela identifica já a legitima. Em suma, esse uso do inglês foi construído localmente, com uma nova pronúncia e um novo sentido, tudo em função de uma prática local de linguagem que demandava tais adequações para ocorrer.

Clemente e Higgins (2008) também tratam de uma reapropriação linguística por estudantes de Inglês como língua adicional, descrevendo como alunos mexicanos usam o falso cognato donkey para criticar amistosamente o desempenho acadêmico uns dos outros. Esses usos alternativos do inglês em diferentes partes do mundo (Brasil, Inglaterra e México) coincidem quanto a seus propósitos: em todas elas os alunos usam a língua adicional de forma inventiva quanto à estrutura e ao significado, engajando em propósitos de integração social e também de aprendizagem.

Em outra prática de um caráter semelhante, Daniel e Juliano parodiavam a pronúncia de uma colega, Camila, tendo por base a pronúncia que consideravam "correta" ou "padrão". Camila, 15 anos à época da pesquisa, sentava-se próxima aos meninos. Ela gostava de cantarolar músicas em inglês durante as aulas, o que foi suficiente para se tornar alvo de brincadeiras como estas:

"não é how are you, é ' $\chi \varnothing \boxminus$ ari iou/"” - disse Daniel, tentando "corrigir" a professora, numa referência

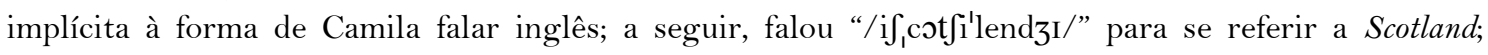
"/'plaia/" para se referir a player. Em outra ocasião, Camila é chamada ao quadro pela professora, ao que os meninos olham para ela e não perdem a oportunidade: "/zॄtfi upi nou/' Camila!" (NOTAS DE CAMPO, 03/10/2011).

Daniel reinventava empoderadamente o inglês ao usá-lo em seu clique, mas por meio dessa reinvenção também censurava a autoridade da colega Camila sobre o idioma. Seu comportamento, lúdico que era, poderia até criar um vínculo mais estreito com a colega, mas as piadas deslegitimavam o inglês da aluna. No trecho da entrevista a seguir, trato do tema com ele:

Igor: [...] Vocês brincavam com o inglês falando “/3દt $\int \mathrm{i}$ upi nou/" , mas porque vocês faziam isso?

Daniel: Ah, porque eu acho legal, assim. Acho engraçado também. A gente falava isso na maioria das vezes porque tinha uma garota lá na sala lá, Camila. Ela começava a cantar umas músicas lá e começava a cantar errado, com a pronúncia errada, aí a gente achava engraçado e ficava zoando dela, daí. $[\cdots]$

Igor: E... O que vocês faziam para provocar ela por ela falar errado? Daniel: Tinha uma tal de... Nobody gonna see us together, lá, de uma música, aí em vez de falar "body”, que é corpo, ou junto, aí essas coisa, ela falou “/bodfi/”, parece, aí começou a zoar, assim. Ficamo rindo. Aí começou com essa história de "/3દt $\mathrm{i}$ upi/”, essas coisa. Igor: Ah, foi por causa dela, por causa dela cantando em inglês na sala. Daniel: Sim. Cantando errado. Aí começamo a falar as coisas errada pra zoar ela, assim. Falamo que era “camilagem”, daí. (ENTREVISTA, 09/03/2012).

A linguagem de Juliano e Daniel construía uma identidade local para aquele grupo, não só pelas imitações como pelo próprio neologismo camilagem, um símbolo das brincadeiras, da pronúncia marginalizada e da cumplicidade deles. Esses alunos usavam seu clique "como casas seguras onde eles podiam brincar com ambas as línguas" (CLEMENTE; HIGGINS, 2008, p.3) ${ }^{9}$, neste caso, inglês e português - ou por que não dizer, ingleses e portugueses.

O teor das diferentes brincadeiras, entretanto, era diferente, pois Daniel toma posições bem distintas com relação ao inglês brasileiro da colega de turma e ao inglês coreano dos jogos online, por exemplo. Ele fazia paródia de uma variante e a rotulava como "errada", enquanto compartilhava um jogo com falantes da outra variante e a entendia como "diferente". Essa discrepância ao se deparar com diferentes ingleses aponta que as práticas alternativas de linguagem dos alunos podem ter propósitos mais ou menos empoderados, ou seja, mais ou menos criticamente informados. Isso demonstra como

\footnotetext{
8 Retirado de http://dictionary.cambridge.org/dictionary/british/manure?q=manure (acesso em 15/04/2011). Escolho essa variante padrão por sua influência no Brasil, derivada do imperialismo (linguístico) provindo dos EUA.

9 No original: “[ $\ldots]$ as safe houses where they can play with both languages”.
} 
[...] é perigoso simplesmente romantizar os textos e discursos dos alunos. [...] O comportamento e os discursos de alunos frequentemente mostram uma mistura de tendências oposicionais e acomodativas, as quais precisam ser criticamente desveladas com relação a seus valores ocultos e implicações. (CANAGARAJAH, 1997, p.193).

Esses ingleses de diferentes motivações e implicações alteravam a experiência escolar e o uso do idioma dentro e fora da escola. Através do humor e da ironia (SCOTT, 1985 apud CANAGARAJAH 1999, p.92), por meio do inglês coreano e do inglês brasileiro, as aulas e a própria língua eram reinventadas naquelas práticas sociais. Isso influenciava os alunos protagonistas desses ingleses, colegas de sala, a professora e também o currículo escolar, ainda que de forma periférica. Dessa forma, vozes subversivas tornavam um ensino/aprendizagem de orientações potencialmente utilitárias, focadas em uma língua de grande incidência imperialista, em uma prática mais local e empoderada, ainda que aparentemente carente de problematizações para torná-la mais complexa quanto a seus propósitos. Tal problematização, entretanto, encontra um excelente cenário para acontecer dentro da sala de aula de língua adicional.

\section{CONSIDERAÇÕES FINAIS}

Práticas de linguagem construídas localmente favorecem à reapropriação local de uma língua. Como este trabalho buscou demonstrar, essa reapropriação pode ocorrer via uso inventivo da língua no tocante à sua finalidade, significado e estrutura; essas práticas de linguagem criativas produzem novas línguas e identidades. Inovações linguísticas frequentemente ocorrem por meio do que escolho aqui chamar de "janelas subversivas", tais como brincadeiras, jogos e piadas; essas janelas, por sua vez, manifestam-se mais abertamente em cliques e casas seguras. Em tais contextos mais subversivos e reservados, práticas alternativas de linguagem podem ter um caráter criativo, ousado, seguro e prazeroso.

$\mathrm{O}$ uso inventivo de ingleses demonstra que podemos repensar a importância de variantes hegemônicas na escola. Modelos dominantes são importantes para o processo de ensino/aprendizagem de língua adicional, mas os ingleses construídos localmente também ditam práticas sociais das mais diversas ordens. Eles estão em voga em sala de aula e mundo afora, exigindo uma sensibilidade intercultural de falantes que jogam online, ouvem uma piada ou quem sabe até participam de uma conferência internacional. Por fim, vale ressaltar que os ingleses que os falantes produzem podem servir não só para recriar práticas e mundos possíveis em seus contextos imediatos, mas também para empoderar o contato com variantes hegemônicas. A investigação e a reflexão sobre o uso de ingleses junto a alunos podem tornar a prática pedagógica em língua adicional ainda mais empoderada do que seus usos subversivos já parecem indicar na Escola do Desterro.

\section{REFERÊNCIAS}

AUSTIN, J. L. How to do things with words. Oxford: Oxford University Press, 1962.

BRUCKERHOFF, C. E. Between classes: the faculty life at Truman high. New York: Teacher College Press, 1991.

CANAGARAJAH, Suresh. Safe houses in the contact zone: coping strategies of African-American students in the academy. College Composition and Communication, v. 48, n. 2, p.173-196, 1997.

Resisting linguistic imperialism through language teaching. China: Oxford University Press, 1999.

. Subversive identities, pedagogical safe houses and critical learning. In: NORTON, B.; TOOHEY,

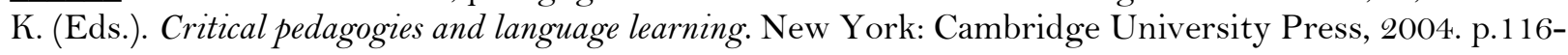
137. $218,2006$.

Negotiating the local in English as lingua franca. Annual Review of Applied Linguistics, v. 26, p.197-

Foreword, p.ix-xiii. In: CLEMENTE, Angeles; HIGGINS, Michael J. Performing English with a postcolonial accent: ethnographic narratives from Mexico. London: The Tufnell Press, 2008. 
Identidades subversivas, zonas pedagógicas de segurança e aprendizagem crítica. Tradução de Beatriz Fontana; revisão da tradução de Lucia Rottava. Em Aberto, Brasília, v. 22, n. 81, p. 113-134, ago. 2009.

CLEMENTE, Angeles; HIGGINS, Michael J. Performing English with a postcolonial accent: ethnographic narratives from Mexico. London: The Tufnell Press, 2008.

CORACINI, Maria José Rodrigues Faria. O discurso publicitário sobre escolas de língua e a constituição da identidade. Letras $\mathcal{E}^{2}$ Letras, Uberlândia, v. 19, n. 1, p. 53-74, jan/jun. 2003.

FONTANA, B.; ROTTAVA, L. Identidades subversivas, zonas pedagógicas de segurança e aprendizagem crítica. Brasília: INEP, 2009.

GADIOLI, Igor. Práticas Subversivas na escola pública: resistência e acomodação na agência de alunos dentro e fora da aula de Inglês. 220f. Dissertação (Mestrado em Linguística Aplicada) - Universidade Federal de Santa Catarina, Programa de Pós-Graduação em Linguística, Florianópolis, 2012.

JORDÃO, Clarissa Menezes. A língua inglesa como "commodity”: direito ou obrigação de todos? CONGRESSO LUSO-AFRO-BRASILEIRO DE CIÊNCIAS SOCIAIS, 8., Setembro de. 2004. Anais... Disponível em: http://www.ces.uc.pt/lab2004/inscricao/pdfs/grupodiscussao32/ClarissaJordao.pdf. (Acesso em 06/05/2012).

MOITA LOPES, Luiz Paulo. Inglês e globalização em uma epistemologia de fronteira: ideologia lingüística para tempos híbridos. DELTA, v. 24, n. 2, p. 1-15, 2008.

PENNYCOOK, Alastair. Performativity and Language Studies. Critical Inquiry in Language Studies: An International Journal, v. 1, n. 1, p. 1-19, 2004.

. Language as a local practice. London; New York: Routledge, 2010.

PRATT, Mary Louise. Arts of the contact zone. Profession, v. 91, p. 33-40, 1991.

RAMPTON, Ben. Language in late modernity: interaction in an urban school. New York: Cambridge University Press, 2006.

SHARIFIAN, Farzad. English as an International Language: perspectives and pedagogical issues. In: EDWARDS, Viv (Ed.). New perspectives on language and education. Bristol; Buffalo; Toronto: Multilingual Matters, 2009.

Recebido em 11/11/13. Aprovado em 19/12/13. 